\section{POSITION STATEMENT Managing Wildlife Trade in the Context of Covid-19 and Future Zoonotic Pandemics}

\section{Issue}

COVID-19 is causing widespread human suffering, as the most acute global public health emergency of our generation. While the origin of the novel coronavirus that causes COVID-19 remains uncertain, several wild species (particularly bats) are known to be important hosts for this family of zoonotic diseases. More generally, there is strong evidence that zoonotic disease emergence is linked to human activities which bring wildlife, domestic animals and humans into increasingly intense contact. This includes destruction and degradation of natural areas; intensive livestock rearing; and hunting, trade and consumption of high-risk wildlife (e.g. bats and primates).

\section{Recommendations}

To minimise the risks of future zoonotic outbreaks, whilst also protecting wildlife, ecosystems and human well-being, we need to rebalance our relationship with nature, using an evidence-based approach to manage the risks associated with global food systems. With specific reference to zoonotic animal-origin viruses such as coronaviruses, we therefore recommend the:
Prevention of illegal, unsustainable, unhygienic and high-stress use of domestic and wild animal species. This will improve animal welfare, support conservation and reduce public health risks. This is regardless of end-use (whether it be for food, medicine or pets).

Support of well-regulated, sustainable and cruelty-free trade in wildlife, based on

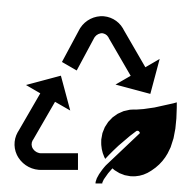
evidence that a particular trade is helping to protect wildlife and their habitats against threats whilst meeting livelihoods and food security needs.

Limitation of destruction of natural ecosystems for

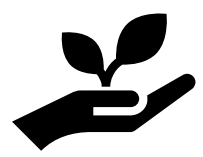
agriculture, mining, infrastructure development and urbanisation, working towards halting further loss and restoring nature.

\section{Better management of} industrial agriculture, to

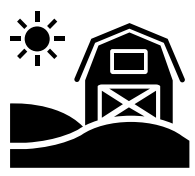
prevent disease outbreaks in humans and livestock, animal welfare issues, pollution of the land and watercourses, and antibiotic resistance. 


\section{Reasoning}

In contrast to our recommendations, many conservation and animal welfare organisations are now calling for complete, long-term bans on wildlife trade and consumption, as a means to reduce the risk of future zoonotic pandemics. We recognise that trade in some wild species represents a risk to public health. However, we express concern at the dominant discourse which focusses solely on the links between zoonosis emergence and wildlife trade and caution against a blanket approach to wildlife trade regulation. Instead, we advocate for a more nuanced and evidence-based approach which could better serve both people and wildlife. Our reasons are:

There is a need to address all the root causes of zoonotic disease emergence, as opposed to taking a narrow focus on wildlife trade.

Available evidence suggests that wildlife use is one of a growing number of anthropogenic drivers, such as industrialised livestock farming (particularly in temperate regions), agricultural intensification and land use change (particularly in tropical regions, where wildlife biodiversity is high). These issues lead to increases in wildlife-livestockhuman interfaces and declines in biodiversity, both of which increase disease transmission, and are further exacerbated by climate change and global supply chains (i.e. the trade and movement of people and animals). Policy interventions need to address all of these root causes if they are to be successful in reducing the transmission of zoonotic diseases globally.
Long-term policy change should be based on sound evidence:

While some organisations are claiming that wildlife trade should be banned on public health grounds, there remains no conclusive evidence about the relative impact of banning all wildlife trade in preventing the emergence of zoonotic diseases in the future. Different organisations are taking slightly different views on what "wildlife trade" is, and which elements should be banned, but the trade in wildlife is multifaceted and heterogeneous. Poorly considered blanket bans could therefore result in unintended negative consequences for both people and wildlife. Past attempts at bans on all wildlife trade and consumption across Africa following the 2013-2016 Ebola crisis resulted in a loss of trust between local communities and conservation NGOs. Other past bans were only transiently effective due to a lack of enforcement capacity and viable alternatives, and were quickly followed by a marked increase in wild meat hunting compared to hunting rates prior to the ban.

Overly hurried interventions can inadvertently do more harm than good.

Immediate crisis management responses to the COVID-19 outbreak, such as closing China's urban wildlife markets, are warranted. However, longer-term policy change, particularly where policy interventions seek to be scalable and generalisable (e.g. across geographies and zoonoses) should not necessarily be based on extreme cases. Further information should be gathered on the public health 
risks of wildlife trade, and the potential perverse consequences of new laws and regulations on other aspects of public health, human well-being, and environmental sustainability. For example, banning all wildlife trade and consumption could damage the livelihoods and food security of millions of people, threaten biodiversity, and drive further land-use intensification for agricultural and livestock production. Conversely, maintaining well regulated, legal trade for species that can be safely and sustainably harvested can help to secure wildlife habitats in some areas, thereby avoiding the very land use changes that drive emergence of zoonoses.

\section{Global problems need international solutions.}

The wildlife trade can be conceptualised by people living in Europe and North America as something that other people do, which makes it easier to call for draconian action. However, wildlife is used all around the world; including game hunting for food and recreation in Europe and North America. The real issue is the way that we use natural resources as a species - whether this be our use of agricultural products such as Soy and Palm oil, our production and consumption of livestock, or our use of wildlife. We no longer mainly eat what we produce locally, and consumer decisions in affluent countries have large impacts on land use change in wild habitats on the other side of the planet. The ecological footprint of consumers in the Global North is much higher than those in the Global South. Viewing the emergence of COVID19 as an issue that has been created 'over there' absolves us of the need to reevaluate our own consumption. The truth is that consumption choices in affluent countries can have huge impacts on the spread of emerging zoonotic diseases on the other side of the world.

\section{Conflation of issues, misinformation and opportunism.}

We note that the organisations calling for bans on wildlife trade are primarily conservation and animal welfare organisations. These calls can seem like opportunistic use of COVID-19 to further their own objectives, which are only tangentially related to public health. Public health, illegal wildlife trade, biodiversity conservation and animal welfare are all important issues, but they are not completely overlapping. There is a need to disentangle the relationships between these (sometimes competing) priorities and consider difficult and context-specific issues relating to sustainability and ethics, rather than calling for one-size-fits-all policies at a time when people and governments are in crisis-management mode.

Consider the voiceless - bring the people affected to the discussion table.

The loudest calls for bans on wildlife trade come from NGOs in the USA and the UK. However, the people who will be affected by these bans include indigenous groups and local communities in poorer countries who rely on the wildlife trade for their livelihoods. No policy should be made without their active, prior involvement. It is not enough to say that their needs will be considered after the fact. 
If we are to protect people around the world against the emergence of further zoonotic diseases, we must learn from past experience. We must better understand the pathways to infection and the various ways in which our activities contribute to pandemic disease risk, to help ensure that policy changes are driven by evidence, and that subsequent actions are both socially just and realistic. At this time of global emergency, we need to focus on controlling the pandemic and alleviating the suffering being endured by people worldwide. Now is not the time to be calling for global bans on wildlife trade, but when the time is right a more nuanced and evidence-based approach can be taken, which will both reduce risks to public health, conserve wildlife and natural systems, and improve the welfare of domestic and wild animals.

\section{Other References}

Members of the team have written more detailed blogs on this topic, available here:

The covid-19 response and wild meat: a call for local context

Coronavirus: why a blanket ban on wildlife trade would not be the right response

On COVID-19, and rebalancing our relationship with nature

Proactive engagement with wildlife trade issues in an unsettled world

China's Announcement on Wildlife Trade What's New and What Does It Mean?

Visit ICCS and COVID-19 for latest updates

\section{Contributors}

This position statement was jointly prepared and agreed by members of the the Oxford Martin Programme on the Illegal Wildlife Trade and Interdisciplinary Centre for Conservation Science, with particular contributions from E.J. Milner-Gulland, Hollie Booth, Lauren Coad and Stephanie Brittain.

$\triangle$ For further enquiries, please contact: ej.milner-gulland@zoo.ox.ac.uk

\section{Suggested Citation}

Oxford Martin Programme on the Illegal Wildlife Trade and Interdisciplinary Centre for Conservation Science. 2020. Position Statement: Managing Wildlife Trade in the Context of Covid-19 and Future Zoonotic Pandemics. Tools and Guidance, University of Oxford. DOI: 10.31219/osf.io/r5w46 